\title{
A Lei de Cotas (12.711/12) está sendo efetiva, eficiente e eficaz? Uma análise seguida de proposta de avaliação a luz da Teoria da Administração Pública gerencialista
}

\author{
Is the Quota Law (12.711/12) being effective, efficient and efficacious? An analysis followed by an \\ evaluation proposal in light of the Theory of Managerial Public administration \\ ¿La Ley de Cuotas (12.711/12) es efectiva, eficiente y eficaz? Un análisis seguido de una propuesta \\ de evaluación a la luz de la Teoría de la Gestión Pública gerencial
}

Recebido: 21/01/2021 | Revisado: 18/01/2021 | Aceito: 22/01/2021 | Publicado: 28/01/2021

Rafael Rodolfo Sartorelli Sadocco
ORCID: https://orcid.org/0000-0002-2051-379X
Universidade Federal de Lavras, Brasil
E-mail: rafael.sadocco@ gmail.com
Lídia Maia Moreira
ORCID: https://orcid.org/0000-0001-9525-0341
Universidade Federal de Lavras, Brasil
E-mail: lidiamm172@gmail.com
Marcelo Oliveira Junior
ORCID: https://orcid.org/0000-0001-9683-4306
Universidade Federal de Lavras, Brasil
E-mail: marcelo.junior2@estudante.ufla.br
Mariane Beatriz Silva Teixeira
ORCID: https://orcid.org/0000-0002-8072-3051
Universidade Federal de Lavras, Brasil
E-mail: marianebteixeira@ @mail.com
Elivelton Luiz Semião Ferraz
ORCID: https://orcid.org/0000-0002-0981-2297
Universidade Federal de Lavras, Brasil
E-mail: eliveltonferraz@live.com

\section{Resumo}

Entender como as Leis, projetos públicos, programas sociais estão de fato impactando a sociedade, se estão funcionando e se estão sendo bem avaliados é imperativo para o novo gestor público. A nova administração pública, desde a década de 1980 requer cada vez mais a utilização do conhecimento científico para se validar, e uma das ferramentas para isso é a utilização do modelo de eficiência, eficácia e efetividade. Assim, este trabalho buscou realizar uma análise por essa perspectiva da Lei de Cotas 12.711/12, interpretando trabalhos que a avaliaram. Concluiu-se que a Lei de Cotas tem sido eficaz no que tange a entrada de alunos beneficiados nas IES, e que os cotistas estão tendo rendimento acadêmico similar aos não-cotistas. Todavia, nenhum trabalho abordou corretamente a eficiência e a efetividade, gerando distorções interpretativas da realidade favoráveis a permanência da Lei, fato que este artigo busca mitigar por destrinchar que faltam dados sobre sua efetividade e eficiência. Em paralelo, criou-se uma proposta de modelo de árvore, que permitiria futuras avaliações sobre a Lei.

Palavras-chave: Lei de Cotas; Administração Pública Gerencial; Efetividade, eficiência e eficácia.

\begin{abstract}
Understanding how the Laws, public projects, social programs are in fact impacting society, if they are working and if they are being well evaluated is imperative for the new public manager. The new public administration, since the 1980 s, increasingly requires the use of scientific knowledge to validate itself, and one of the tools for this is the use of the efficiency, efficacy and effectiveness model. Therefore, this work sought to carry out an analysis from this perspective of the Quota Law 12.711/12, interpreting works that evaluated it. It was concluded that the Quota Law has been effective with regard to the entry of benefited students in HEIs, and that quota students are having similar academic performance to non-quota students. However, no work has correctly addressed efficiency and effectiveness, generating interpretive distortions of reality favorable to the permanence of the Law, a fact that this article seeks to mitigate by unraveling data on its effectiveness and efficiency. In parallel, a proposal for a tree model was created, which would allow future evaluation of the Law.
\end{abstract}

Keywords: Quota Law; Managerial Public Administration; Effectiveness, efficiency and efficacious. 


\section{Resumen}

Entender cómo las leyes, los proyectos públicos, los programas sociales están impactando de hecho en la sociedad, si están funcionando y si están siendo bien evaluados es imperativo para el nuevo administrador público. La nueva administración pública, desde la década de los 80 , requiere cada vez más el uso del conocimiento científico para validarse, y una de las herramientas para ello es el uso del modelo de eficiencia, eficacia y efectividad. Así, este trabajo buscó realizar un análisis desde esta perspectiva de la Ley de Cuotas 12.711/12, interpretando los trabajos que la evaluaron. Se concluyó que la Ley de Cuotas ha entrado en vigencia con respecto al ingreso de estudiantes beneficiados en las IES y que los estudiantes de cuotas están teniendo un desempeño académico similar a los estudiantes que no lo son. Sin embargo, ningún trabajo ha abordado correctamente la eficiencia y efectividad, generando distorsiones interpretativas de la realidad favorables a la permanencia de la Ley, hecho que este artículo busca mitigar desentrañando datos sobre su efectividad y eficiencia. Paralelamente, se elaboró una propuesta de modelo de árbol, que permitiría futuras evaluaciones de la Ley.

Palabras clave: Ley de Cuotas; Administración Pública Gerencial; Efectividad, eficiencia y eficacia.

\section{Introdução}

Nas duas primeiras décadas dos anos 2000, ocorreu vertiginosa expansão no número de vagas no ensino superior no Brasil. Na rede privada, o número cresceu mais de seis vezes em pouco mais de dez anos, atingindo a oferta de quase seis milhões de vagas presenciais e cerca de quatro milhões e meio à distância em 2017. Já as vagas na rede pública passaram a somar pouco mais de 800 mil, ou, 7,64\% das vagas totais (MEC, 2018). Cardoso (2016) expõe que essas universidades públicas contam com a união de três fatores de destaque - escassez (poucas vagas disponíveis), qualidade (excelentes números em todos os indicadores) e gratuidade - e em virtude disso, agigantou-se a concorrência dos educandos por vagas nessas Instituições de Ensino Superior (IES) públicas ao longo de toda sua história. Segundo esse autor, elas apresentam uma média de 21,3 candidatos por vaga, bem distante da relação média de 2,3 nas instituições particulares (lembra-se que isso são médias aritméticas simples, dado que em muitos cursos públicos a competição é muito maior e que muitas universidades privadas não têm concorrência alguma). Assim, para conseguir uma vaga na rede pública, exigir-se-ia que os alunos estivessem muito bem preparados para competir nos vestibulares, o que é muito estimulado pelo ensino médio privado, e pouco pelo ensino público, o que resultava historicamente no fato de que só aqueles conseguiam disputar as vagas principalmente antes da expansão das vagas universitárias (Cardoso, 2016).

A fim de cambiar esse cenário, algumas ações começaram a ser pensadas, dentre elas, as denominadas ações afirmativas. Em relação as ações afirmativas por renda e "raça", essas começaram com as universidades estaduais do Rio, sendo a Universidade Estadual do Rio de Janeiro (UERJ) a pioneira em 2001, com 40\% de cotas para negros, seguida pela Universidade Estadual do Norte Fluminense. Nos anos seguintes, essas ações foram implementadas individualmente em outras 51 instituições educacionais públicas em todo o país. Foram também criadas leis estaduais, como a Lei Ordinária Estadual 5.346 (Rio de Janeiro, 2008), de 11 de dezembro de 2008, do Governo do Rio de Janeiro, que preconizou vagas para alguns grupos, como negros, indígenas, deficientes e filhos de policias e bombeiros mortos no exercício da função.

Outras ações foram sendo adotadas, chegando no que foi conhecido como Reforma Universitária, iniciada em 2004 . O Prouni, carro-chefe da reforma, foi instituído em 2005 e criou um sistema de parcerias com as IES privadas, consentindo que essas disponibilizassem bolsas parciais e integrais exclusivamente para concluintes do ensino médio público, que poderiam ser divididos em diversos subgrupos (Ribeiro \& Guzzo, 2017; Catani, Hey \& Gilioli, 2006). Criou-se também o Programa de Apoio a Planos de Reestruturação e Expansão das Universidades Federais (Reuni), por meio do Decreto Presidencial 6.096, de 24 de abril de 2007, almejando aumentar tanto a disponibilidade de vagas, como o quantitativo de cursos noturnos, incentivo as inovações pedagógicas e combate à evasão (Casa Civil, 2018).

Porém, segundo Basso-Poletto, Efrom e Beatriz-Rodrigues (2020), essas ações começam a ganhar profundo interesse acadêmico somente a partir da implementação da Lei 12.711 de 2012. Essa lei condensou as diversas propostas singulares em um regramento geral de ações afirmativas, norteando todas as Instituições de Ensino Superior (IES) federais e dando as bases 
para as demais universidades estaduais. As cotas seriam válidas por um prazo inicial de dez anos, reservando um mínimo de 50\% de vagas para alunos que tenham cursado inteiramente o ensino médio em escolas públicas, e a partir disso, subdivisões, sendo: metade para alunos com renda familiar bruta igual ou menor a um salário mínimo e meio, e a outra metade independeria da renda; nos dois cenários, haveria um percentual mínimo reservado para a soma correspondente de índios, pardos e pretos no estado onde a instituição está localizada (MEC, 2020).

Baseando-se nisso, e partindo da perspectiva da nova administração pública gerencialista, almejou-se aqui, realizar um estudo que pudesse estruturar elementos que refletissem sobre a mensuração da efetividade, eficiência e eficácia da lei de cotas, baseando-se assim nas seguintes perguntas de pesquisa: a política de cotas para a entrada no ensino superior vem sendo efetiva, eficiente e eficaz pela perspectiva da administração pública gerencialista? Quais os mecanismos adequados para mensurar a efetividade dessa lei? Quais tem sido as interpretações dos estudos e relatórios sobre os 3E’s da lei? É possível montar um modelo para interpretar essa lei baseado nos 3E's? As respostas desses questionamentos permitiriam atingir o objetivo deste estudo final, que é elaborar uma proposta de avaliação da lei de cotas, que seja amplo o suficiente para analisá-la como um todo, e não apenas para verificar os desempenhos de determinados beneficiários em universidades específicas. Assim, este trabalho tem caráter exploratório propositivo. Observa-se que essas aplicações justificam a realização deste trabalho, uma vez que ele reverbera tanto para pesquisadores das áreas de administração pública, ciência política e educação, como para gestores públicos e legisladores. Mesmo assim, tem sua contribuição teórica, dado que esse tipo de reflexão ainda não fora estudada e apresentada até agosto de 2020.

\section{Metodologia}

Optou-se aqui por um estudo de abordagem qualitativa com caráter descritivo, que conforme Pereira et. al. (2018, p.67) são "aqueles nos quais é importante a interpretação por parte do pesquisador com suas opiniões sobre o fenômeno em estudo", e é caracterizada como pesquisa exploratória, que assim como dito por Vergara (2009), é utilizada quando há poucos estudos voltados à temática pesquisada e pode contribuir, igualmente, para elevar o grau de familiaridade com fenômenos relativamente desconhecidos e obter informações sobre um contexto particular da vida real.

Para atingir os objetivos propostos, far-se-á aqui uma revisão de literatura. A revisão de literatura é um método que permite a ampla compreensão sobre o tópico, identificando o estado da arte do conhecimento científico, induzindo as novas teorias, identificando também lacunas e temas sobre um assunto especifico, de forma organizada, que permita a discussão sobre o tema abordado. Existe um amplo leque de modelos de revisão de literatura, sendo a revisão bibliográfica (também conhecida como revisão narrativa), uma das mais comuns, dado que sonda o que há disposto nos acervos da literatura (Botelho, Cunha \& Macedo, 2011). Cordeiro (2007), apresenta que a revisão narrativa, diferentemente da revisão sistemática, tem uma temática mais ampla, sem que seja exigida uma questão muito específica, ou seja, abriria mão de um protocolo mais rígido, o que autoriza a seleção dos artigos de maneira arbitrária, ao passo que permite que o autor do texto tenha maior interferência na seleção de cada texto.

Moreira (2004) acrescenta que como a produção cientifica tende a ser um trabalho cumulativo, requer-se uma leitura de como o tema já fora trabalhado anteriormente para elucidar e ampliar novos ensaios. Ou seja, revisar implicaria em olhar novamente o que outros pesquisadores já encontraram e propor uma releitura, e não apenas as críticas. Isso se faz possível através de objetivos claros. A revisão permite posicionar tanto o pesquisador como o leitor de seu trabalho sobre o momento vigente do assunto abordado, dando clareza sobre o que avançou, o que regrediu, qual a atual significância, etc.

Logo, a revisão de literatura parece ser adequada para esta campanha, posto que contemplará inicialmente a administração pública gerencial, passando pela reforma da administração pública e importância dos 3E's neste cenário. Avançar-se-á para refletir sobre os instrumentos e métodos de verificação de êxito de leis. Posteriormente, revisar-se-á as 
políticas de acesso ao ensino superior, que foram mapeadas e explicadas em sua historicidade, juntamente com as leituras feitas sobre como essa lei tem se saído. Ao final, somando-se os dois conceitos, propor-se-á um modelo avaliativo de como se mensurar tais ações para que possam ser adotados em pesquisas futuras, ou até mesmo na prática, por funcionários públicos.

\section{Revisão de Literatura}

\subsection{A administração pública gerencial}

Cunha (2018), diria que a literatura tem chegado a um consenso de que os estudos voltados para a avaliação de políticas e programas públicos ganharam pujança na transformação da Administração Pública nos anos 1980 e 1990, para que essa se tornasse mais moderna e eficiente, principalmente motivada pela onda neoliberal, muito em razão do colapso do comunismo. Dado isso, começar-se-á abaixo, uma abreviada explicação histórica sobre como se chegou a esse contexto.

A administração pública principia a se desprender da ciência política há menos de um século, formando-se nos Estados Unidos, e perscrutando assim a maturação de uma "ciência mais aplicada, com ênfase em análises científicas de fenômenos sociais, e diretamente ligada ao aumento do tamanho, funções e atividades desenvolvidas pelos Estados nacionais" (Brasil, Cêpeda \& Medeiros, 2014, p.2). No Brasil, até os anos 1930, tal disciplina era encontrada majoritariamente em outro campo, o do direito administrativo. Nesse período, contudo, a história da administração pública começa a se distanciar tanto da política como do direito administrativo, para ir além da criação e aplicação das leis e sim para administrar a coisa pública. Desde a década de 1930, já se exaltava a necessidade de desenvolvimento de pessoas capacitadas para conhecer o Brasil e gerenciar os negócios públicos de maneira estratégica, a fim de ajudar a modernização da sociedade brasileira. Porém, esse caminho é mais tortuoso do que aparenta acima, e merece alguma reflexão, iniciando pela tentativa de rotular os três grandes modelos que marcaram a administração pública no Brasil: o período pré-burocrático, o momento burocrático e o gerencial (Brasil, Cêpeda \& Medeiros, 2014).

Ao se esmiuçar um pouco mais esses três tipos, vê-se que o modelo pré-burocrático é originado do patrimonialismo típico do sistema monárquico absolutista, onde o serviço púbico ineficiente carregava em si fortes traços de pessoalismo, já que era uma extensão da propriedade do rei. Contudo, lembra-se que o Estado era limitado à época, com poucas obrigações e braços. Conforme ele cresce, o modelo burocrático do exército prussiano, tal como descrito por Weber, ganha espaço e começa a ser implementado tanto na Europa do final do século XIX, como nos EUA no começo do século XX. Nesse contexto, a burocracia deixava todos iguais, atendendo aos problemas existentes de maneira sistemática e robótica, ou seja, dava impessoalidade as funções públicas. O modelo foi funcional a princípio, cumprindo sua parte. Mas como esperar que tarefas complexas, em um mundo que demandava mais e mais serviços, em um estado crescente, imediatista, assistencialista, onde as mudanças são rápidas, se baseasse num sistema cuja lentidão se avolumava, e suas receitas para problemas antigos se debruçavam em mais burocracia? Assim, o resultado foi desastroso, repercutindo em uma série de crises, nas quais se destacariam a crise dos anos 1970 e 1980, que foram somadas a crise do Petróleo. Percebeu-se assim, que se necessitava de um novo modelo, bem mais ágil (Osborne \& Gaebler, 1994), que será abordado após breve apresentação do caso brasileiro.

Esse mesmo trajeto pode ser percebido no Brasil. A administração pública por aqui começa a ganhar bons contornos com a chegada da corte portuguesa em 1808. O modelo da administração metropolitana é transportado de Lisboa, reformulando os diversos tipos de organismos destrambelhados que até então compunham o aparelho de estado brasileiro. Esse aparato - pré-burocrático - era basicamente sustentado nos costumes e nas tradições emanadas do rei e da nobreza, com pouco profissionalismo, confusão de atribuições, e cargos assumidos por nobres ou burgueses enriquecidos, ou seja, forte presença das relações pessoais. Com o fim do Império, as relações clientelistas e patrimonialistas se mantiveram. Grandes proprietários de terra, famílias patriarcais, relações clientelistas e um estado centralizador que gerenciava os interesses das muitas regiões, marcaram o Brasil até o fim da Primeira República, em 1930. Porém, mesmo na República, as estruturas socioeconômicas 
brasileiras se mantiveram com forte presença do setor agrário exportador, latifúndios, que com a ascensão do café teve seu centro deslocado do Nordeste para São Paulo. Sem grandes mudanças nas bases estruturantes econômicos, seu reflexo no modelo administrativo público também não se deu. A Revolução de 1930 catapultou a criação de novas instituições, dado que havia um processo de industrialização emergente que passava a demandar outras estruturas administrativas. Ao mesmo tempo, ocorria a perda do poder das elites agrícolas (que resultariam no afastamento das oligarquias da dominação patrimonialista). Esse afastamento do patrimonialismo, das antigas oligarquias, fez-se necessário para selar as bases das reformas administrativas estatais, com o surgimento de agências, juntamente com o liberalismo e o avanço do capitalismo. Assim, com Getúlio Vargas, inicia-se a concepção de que o servidorismo público deveria ser ocupado pelos mais preparados, e não apenas garantido para determinada pessoa por indicação nominal. Obviamente, que para conseguir chegar nesse ideal de justeza, de equiparação, o labor foi longo e moroso, por conseguinte, por vezes muito pouco funcional (Brasil, Cêpeda \& Medeiros, 2014).

Como visto, ainda que tenha perseverado por boa parte do século $\mathrm{XX}$, alguns fatos (além dos já supracitados) marcaram a necessidade da ruptura do modelo burocrático, tanto em termos nacionais como globais. Sublinham-se assim, a crise fiscal, fruto do nacional desenvolvimentismo - que marcou o período do regime militar no Brasil -, os choques do petróleo, a nova concentração de países competidores no mercado internacional e a disputa deles por investimentos (também observada nos governos subnacionais). Portanto, desde os anos 1980, as administrações públicas em todo o mundo começaram a sofrer uma constante pressão para mudar suas políticas de gestão pública. O país pioneiro, Reino Unido, acabou buscando remodelar sua administração pública, caminhando lado a lado com o formato do sistema gerencial neoliberal. Do outro lado do oceano, os valores propagados pelo empreendedorismo tomavam os Estados Unidos, reforçando os modelos administrativos que enalteciam o individualismo, o trabalho duro, a criatividade, etc. O estado passou então a ser planejado não apenas para defender a economia nacional, mas também para prepará-lo para competir internacionalmente em um cenário de mercados globalizado (Secchi, 2009; Bresser-Pereira, 1996; Bresser-Pereira, 2005; Reis, 2014; Paula, 2005).

Portanto, embora as concepções sobre a administração pública gerencial sejam plurais, optar-se-á aqui por compreendê-la pela perspectiva ideológica tal como interpretada por Secchi (2009) e Bresser-Pereira (2005), de que esse é um modelo pós-burocrático, que incorpora prescrições que almejam o aumento da efetividade, eficiência e eficácia da gestão das organizações públicas. Esse gerencialismo traria em si propostas claras, como a de orientação do serviço ao público, voltada para a descentralização das tarefas, eficiência na prestação de serviços, fim do empreguismo, redução dos gastos gerais e da corrupção, etc. (Reis, 2014).

\subsection{A reforma do Estado e a sedimentação do conceito de efetividade, eficiência e eficácia}

No Brasil, a reforma da administração pública começou a se dar nos anos 1990, na gestão do então presidente Fernando Henrique Cardoso, e foi marcada por preceitos neoliberais que traziam em si a ideia de eficiência (Araújo \& Rodrigues, 2012). Todavia, diferentemente da administração privada que tem seu foco no cliente, esta, tê-lo-ia no cidadão. Pontua-se que a ideia de eficiência foi até mesmo chancelada na Emenda Constitucional no 19 de 1998, em seu artigo 37: "A administração pública direta e indireta de qualquer dos Poderes da União, dos Estados, do Distrito Federal e dos Municípios obedecerá aos princípios de legalidade, impessoalidade, moralidade, publicidade e eficiência...” (Brasil, 1998).

Nela, buscava-se melhorar a prestação de serviços aos cidadãos, de maneira mais racional, dando ao setor público uma visão mais econômica. Tornou-se, assim, quase como uma necessidade inquebrantável, que tanto os serviços públicos exclusivos, como não-exclusivos, operassem de maneira mais eficiente, otimizando os recursos estatais e diminuindo os gastos. Outrossim, a burocracia passou a ser reduzida, e os objetivos deveriam ser atingidos de maneira mais rápida e eficaz, 
atendendo as demandas sociais que se encontravam insatisfeitas pela prestação dos serviços públicos (Araújo \& Rodrigues, 2012).

Menezes (2005), por sua vez, complementa que a reforma administrativa brasileira também levantou mecanismos que possibilitassem flexibilizar a estabilidade do servidor público e que estimulassem à participação popular. Igualmente, essa autora coloca que o Estado teve seu papel redesenhado, ora porque as atividades que dependessem do poder estatal seguiriam sendo executadas apenas por pessoas jurídicas de direito público, enquanto aqueles que pudessem ser adimplidos por outros atores privados, poderiam sê-lo, desde que esses particulares se submetessem ao regime jurídico pautado na supremacia do interesse coletivo. Enfatiza-se que essa subdivisão perscrutaria atingir maior eficiência e qualidade no serviço público, avançando sobre a singela ideia de criação de leis. Desse modo, pondera-se que a ideia de eficiência está cravada nas propositivas democráticas, voltadas a otimizar os resultados de sua atuação em respeito aos princípios constitucionais estabelecidos, lembrando a necessidade de controle social, atingido por meio da participação civil (Menezes, 2005).

Ao se elucubrar quanto ao termo eficiência em si, vê-se que isto está relacionado ao bom funcionamento de determinado objeto ou serviço, e que para tanto, saber para que se destina aqueles meios é necessário. Quando se atribui tal terminologia à administração pública, isso também ocorre, entendendo para que fim aqueles produtos se destinam, quem compõem seus públicos, qual seu modo e sua possibilidade de operar. A participação na formulação de políticas públicas e na implementação da gestão dos serviços públicos passa a ser ansiada pelo cidadão em um Estado democrático. Tais fatos, alinhados com os princípios e regras que o regulam, permitiriam que a administração pública fosse percebida como eficiente ao atingir suas finalidades, tais como: ampliação do bem-estar coletivo ou de repartição equitativa da riqueza pelos integrantes da sociedade por meio do menor esforço possível (Menezes, 2005).

Todavia, não é apenas a ideia de eficiência que pauta a administração pública gerencialista. Sano e Montenegro Filho (2013) acrescentam que há o imperativo de se atingir mais os 3E’s como um todo (eficiência, eficácia e efetividade) das ações governamentais, que muitas vezes é restringido pelo não comprometimento dos atores envolvidos na gestão pública e que culminariam na má qualidade dos serviços prestados aos cidadãos. Isso exigiria uma avaliação sistemática, contínua e eficaz baseada em indicadores multicritérios. A ideia de efetividade sugere a utilização de indicadores de múltiplas naturezas e propriedades, de forma a se perquirir lograr as trasnformações globais derivadas das mudanças, inclusive, fazendo uso da abordagem qualitativa, e do tempo total para impacto (Sano \& Montenegro, 2013). Logo, efetividade, seria a apreciação da relação entre a implementação de um projeto e a comparação com seus resultados, no que tange às alterações sociais na vida daqueles que foram atingidos, permitindo compreender se os produtos de uma determinada política pública foram coerentes com seus resultados sociais (Marchesan \& Oliveira, 2019).

Costa e Castanhar (2003), baseados em manual da Unicef reforçam esses pontos: os " 3 e's", eficiência (melhor relação custo/benefício possível para se alcançar os objetivos); eficácia (gradação de aferição de objetivos e metas); efetividade (efeitos positivos, obtidos em campos diversos, como econômico, sociocultural, institucional e ambiental; e também, sustentabilidade, análise custo-efetividade; satisfação do beneficiário; e por fim, equidade). Esses conceitos podem ser lidos de outra forma, como: efetividade é entendida pela avaliação das transformações ocorridas a partir da ação proposta; eficácia resultaria da relação entre aquilo que foi pretendido com aquilo que foi atingido, e a eficiência o máximo que pode ser feito com o mínimo de recursos (Sano \& Montenegro, 2013). Logo, para se avaliar os programas governamentais, deve-se pensar sistematicamente em como avalia-los pelos 3E's, que serão melhor discutidos abaixo.

\subsection{Mensuração e avaliação de políticas públicas}

A concepção de políticas públicas é apresentada por Souza (2007), que relata que essas se encaixam em um campo do conhecimento que atua de maneira analítica, tomando por base o conjunto das ações do governo, considerando como as 
políticas são emolduradas e quais são seus efeitos. Logo, o governo é colocado em ação ao pesquisar demandas e formas de atuação, em paralelo, isso reflete igualmente sobre a percepção dessa política e suas consequências diretas e indiretas.

Como visto, compreender seus efeitos é parte fundamental da ideia das políticas públicas. A avaliação, portanto, é um instrumento para a melhoria da eficiência em uma serie de pontos dentro da administração pública, que vão desde avaliar como o gasto público vem se dando, como também para auferir como se dá o controle social dessa política. Tal importância pode ser concebida ao se perceber as inúmeras tentativas de se criar propostas metodológicas de avaliação, elaboradas pelos mais importantes organismos internacionais, como a ONU, Banco Mundial, BID, OCDE, etc. Deve-se notar que a avaliação não é um esforço único no tempo, nem conduzido de maneira desgarrada de outros processos. Deve ser sistemática, contínua e eficaz, para que assim se torne uma ferramenta poderosa para contribuir com os formuladores de políticas públicas no seu ímpeto em aumentar a eficiência, efetividade e eficácia aplicada aos programas sociais (Ramos \& Schabbach, 2012).

Esse trajeto supracitado - sistemático, contínuo e eficaz - surge como ferramenta gerencial poderosa, fornecendo aos formuladores de políticas públicas e aos gestores de programas condições para aumentar a eficiência e efetividade dos recursos aplicados em programas sociais. Todavia, historicamente, o foco dos programas públicos brasileiros consistia na sua formulação, e não em como implementá-los e verificá-los. Cenário esse que passa a se alterar, como acima referenciado, na década de 1980, com o aumento da dívida externa e encerramento de um ciclo econômico positivo, etc., resultando no aprofundamento das desigualdades sociais no país. Essas desigualdades são acentuadas com as reformas dos anos 1990 (onde ocorreu a desestatização e a abertura comercial) que aos olhos dos autores, culminaram na impulsão do desemprego e precarização dos remanescentes. Logo, a maior demanda por ações governamentais se deu pari passu com a necessidade de se aumentar os 3E's das ações governamentais (Costa \& Castanhar, 2003).

A relevância de se mensurar as políticas públicas, levaram a Casa Civil (2018) do Governo Federal a lançar dois manuais, um para a elaboração de leis ex ant, ou seja, manual que orientaria a preparação da lei, considerando que nesse apresto já se deveria prever métodos de aferição da mesma. O segundo, ex post de políticas públicas, estabelecia mecanismos de orientações com diferentes abordagens para a cadeia de valor das políticas públicas (insumos, processos, produtos, resultados e impactos). O manual faz uma excelente leitura de um programa educacional, o Fies, que será muito caro nesta discussão. Para conseguir criar medidas de verificação dos programas, foi elaborada uma árvore de diagnóstico e uma árvore de objetivos, como apresentado na Figura 1. 


\section{Figura 1.}

\section{Árvore de objetivos}

FIGURA A.2

\section{Árvore de objetivos do Fies}

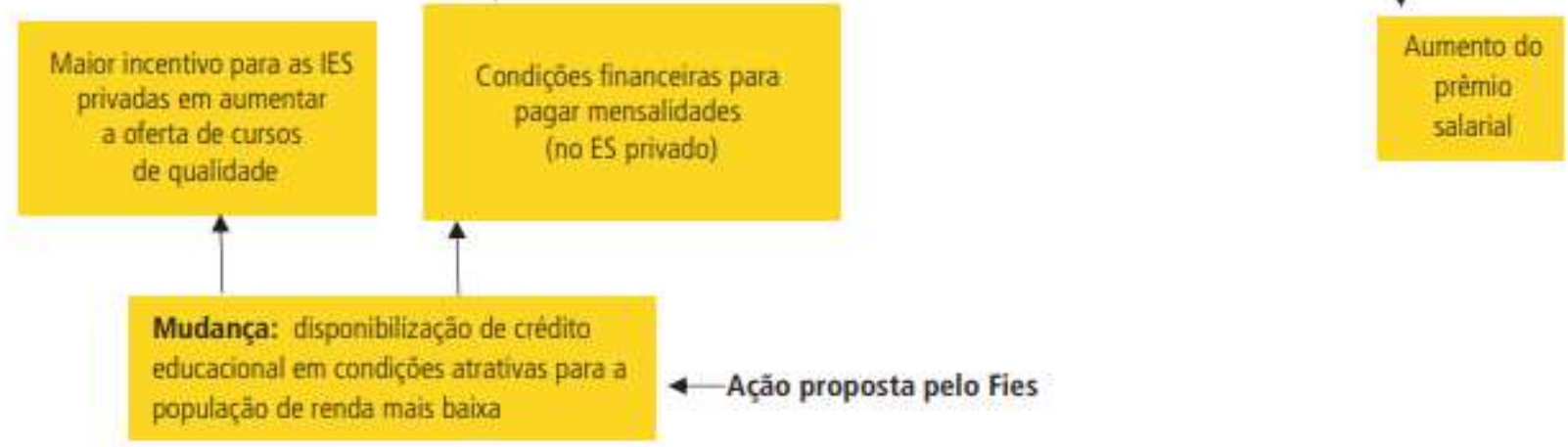

Fonte: Casa Civil (2018)

\section{Apresentação da Avaliação dos 3E's na Política de Cotas e Discussão}

Para permitir uma análise mais apurada, os artigos e textos que apresentam análises das leis serão abordados por tópicos:

- Almeida e Rodrigues (2020) apontam que os programas públicos devem alcançar os objetivos propostos e seus beneficiários. Não apenas isso, mas se deve pensar alguns métodos para visualizar se eles realmente funcionam, e em que níveis e quais os impactos nos beneficiados pelo programa. Esses autores fizeram uma avaliação de impacto visando mensurar com precisão os mecanismos que estão gerando boas respostas nos usuários das leis de cotas na Universidade Federal de Viçosa. Os autores buscaram avaliar a lei de Cotas 12.711/12, mensurando as possíveis diferenças de desempenho do alunado beneficiário pelas cotas, quando comparado com os alunos que entraram por ampla concorrência. Constataram que não houve diferenças significativas entre os dois grupos, o que lhes pareceu um indicativo de que a lei logrou êxito, posto que ampliou o acesso à universidade sem que houvesse diminuição da qualidade de ensino e aprendizado. Neste caso, os autores acabaram exclusivamente refletindo sobre a eficácia da lei, ao mensurar dados numéricos e simples, sem aprofundar a discussão sobre efetividade e eficiência. 
- Marchesan e Oliveira (2019) discutem a reserva de vagas suplementares a Lei 12.712/12 (nos temos do Decreto $\mathrm{n}^{\mathbf{o}}$ 7.824/2012 e da Portaria Normativa $n^{\circ}$ 18/2012 do Ministério da Educação -MEC) adotadas em 2013 pelo Instituto Federal de Educação, Ciência e Tecnologia Catarinense (IFC) no ano de 2013, que reservava 25\% das vagas para o curso Técnico em Agropecuária, que seriam ocupadas apenas pelos estudantes provenientes da atividade agrícola. Primeiramente, os autores tiveram dificuldade para constatar a necessidade da medida, por não terem acesso as notas de entradas dos alunos. Segundamente, investigaram a inserção no mercado de trabalho, mas os dados levantados não proporcionariam grandes reflexões, uma vez que alguns continuaram estudando, outros estavam trabalhando e outros nem uma coisa ou outra. Contudo, discutir se o aluno "está inserido no mercado" é completamente diferente de investigar se ele está inserido na área em que estudou, se está em uma empresa familiar aumentando a lucratividade, se está em uma empresa que o contratou em virtude do currículo, se está usando o conhecimento aprendido, etc.

- Palma (2019), por sua vez, não analisou a Lei de Cotas 12.711/12, mas sim a efetividade da LF nº12.990/2014, que garante cotas para negros na docência do ensino universitário federal. Contudo, embora seu objeto de pesquisa não seja sobre a cota para o alunado, a discussão encontrada em sua tese de doutorado (ainda não publicada em artigos científicos, apenas em artigos de congresso), é muito cara para este estudo, e merece maior digressão. Essa autora encontrou "um verdadeiro flagrante da não efetividade da lei no caso concreto" (PALMA, 2019, p. 232). Nota-se que a autora se refere ao não cumprimento da lei. Os editais deveriam resguardar $20 \%$ para os negros, mas em alguns processos, menos de $4 \%$ das vagas foram destinadas para negros. Na continuidade da leitura da obra, a autora menciona ainda: falta de clareza nos editais, que não apresentam com especificidade os critérios adotados, sem procedimentos padrões, o que pode incidir no desinteresse dos candidatos negros; as vagas destinadas a reserva por cotas não obedecem critérios claros e pré-estabelecidos; falta de registros no que tange aos aprovados pela lei; fracionamento de vagas por editais, onde as Universidades apresentam menos de três vagas por concurso (três seria o número de vagas mínimo para que necessitasse ocorrer a reserva por cotas); número reduzido de abertura de vagas, em razão do deslocamento de docentes; a fragilidade na regulamentação, posto que a Lei só foi regulamentada parcialmente dois anos depois de sua entrada em vigência, e complementada em definitivo em 2018, quatro anos depois, o que resulta em diversos litígios administrativos e judiciais; e por fim, problemas quanto a heteroidentificação, e esse, talvez, o mais sensível, posto que por prerrogativas constitucionais, uma comissão para determinar a heteroidentificação não tem legitimidade para definir a raça do postulante, ou seja, excluí-lo do processo, posto que comissões não podem incluir ou excluir direitos, apenas leis. As comissões ainda não agiriam dentro da proporcionalidade e legalidade, e ainda não pode ser sigilosa, mas também não pode ser publicada, ou seja, um contrassenso em princípio. Novamente, vê-se que a discussão se dá não sobre a efetividade e eficiência, mas sim sobre a eficácia, refletindo sobre os números que diriam que se a meta da lei de cotas está sendo cumprida ou não. Toda a discussão da autora é dentro dessa temática.

- Em nível estadual, a Procuradoria Geral do Estado do Rio de Janeiro (PGE-RJ, 2017), foi a pioneira a esboçar um trabalho para verificar a efetividade da lei. A PGR desse estado solicitou para um Comitê (designado para esse fim), uma análise da efetividade do sistema de cotas instituído pela Lei a 5.346/2008, apresentada na introdução deste artigo, um proto-modelo muito similar ao adotado nacionalmente. O relatório final foi dividido em algumas etapas. A primeira, do ingresso, mostrou que o número de ingressantes negros atingiu um bom crescimento. Todavia, apresentam que o sistema carece de melhorias principalmente no que tange os deficientes e os processos antifraude (nem sequer abordaram os filhos dos bombeiros e filhos dos policiais). O segundo ponto versa sobre o coeficiente de rendimento dos cotistas, que se mostrou próximo dos não-cotistas, o que representaria que as cotas não diminuiriam a qualidade de ensino nas universidades. Mostraram exemplos, como nos cursos de Matemática e Física, onde os 
cotistas chegaram a ficar até $20 \%$ acima dos não-cotistas. No terceiro ponto, que aborda a evasão, mostraram novamente que o número de evadidos é maior entre os não-cotistas do que cotistas, tanto nos cursos presenciais como nos cursos a distância. O quarto ponto é sobre o número de formados, que segue relativamente próximo ao número de vagas destinadas as cotas (contudo, esse número não faz sentido se não for apresentado com o tempo de duração de discentes no curso, dado que se assim não se der, os dados de evasão significariam a mesma coisa). Quanto ao quinto ponto, que versa sobre a inserção dos cotistas e não-cotistas no mercado de trabalho, os dados apresentados são estarrecedores: provêm de uma pesquisa com 300 entrevistados, por uma revista semanal (Revista Veja) não acadêmica (que obviamente, não apresenta claramente a metodologia da pesquisa), comentando que a inserção de ambos os grupos no mercado é similar, na casa dos 75\%, mas que os salários dos não-cotistas giram na casa dos dez mil reais, enquanto a dos não-cotistas é na casa dos sete mil reais. Esses números causam enorme estranheza, dado que são muito acima da realidade brasileira, mas não menciona absolutamente nada sobre há quanto tempo eles se formaram nem que carreiras cursaram. Embora o relatório assuma que os dados não são confiáveis, cobram maior atenção das políticas públicas para além das universidades, como políticas para o ingresso no mercado de trabalho (o que é estranho, já que os dados não são confiáveis). A conclusão do relatório, que é notavelmente sobre eficácia e não eficiência e efetividade (que se apresentaria apenas no fato dos jovens estarem ou não, conseguindo emprego, dados infelizmente não levantados), diz que "O sistema de cotas de ingresso nas universidades públicas do Estado do Rio de Janeiro tem se mostrado bem-sucedido na alteração das profundas distorções históricas na distribuição de oportunidades no quadro econômico, social e político brasileiro" e, ainda, justifica pontuando que "tal alteração demanda tempo e aperfeiçoamento constante, a Comissão de Avaliação da Lei de Cotas recomenda a propositura de novo Projeto de Lei que renove o sistema de cotas." (PGE-RJ, 2017).

- O artigo de Da Costa Garcia e De Jesus (2015), investigou a pauta de êxito acadêmico, e ao fazerem a mesma comparação também constataram que o desempenho dos cotistas e não cotistas se mostraram próximas em cinco dos nove cursos analisados. Novamente, sobre eficácia.

- Guimarães (2014), ao analisar o livro coletânea "O impacto das cotas nas universidades brasileiras (2004-2012)", conclui que todos os autores foram unânimes no que tange a eficiência das cotas para que se aumentasse o número de discentes oriundos de escolas públicas nas universidades públicas, com destaque a presença desses nos cursos mais concorridos ou tradicionais (o termo correto seria eficácia e não eficiência). Contudo, o autor ressalva que isso é óbvio, em razão da forma de seleção (o exemplo levantado por Palma demonstra que isso não é tão óbvio, mas talvez, mais facilmente atingível, típico da eficácia quando destituída dos outros E’s). Isso não se repetiu no caso dos negros, seja por falta de demanda, deficiência no processo de seleção e retenção, ou não atingimento da nota de corte. No que tange aos indígenas, o autor mostra que faltam esforços para melhorar a participação dos indígenas nesses processos. Até então, a obra observa a Lei pelo viés da eficácia. Frisa-se ainda, a necessidade de acompanhamento financeiro e social, como auxílios financeiros e assistência estudantil, para que esses estudantes tenham êxito. O trabalho de Guimarães (2014) aborda leituras mais amplas, porém, ainda fica estreito a ideia de eficácia, posto que o que propõe versa ainda durante a manutenção dos alunos na universidade, e não quanto ao seu custo e impactos sociais.

- No estudo conduzido na UFMG entre 2009 e 2010, antes da implementação da Lei de Cotas, Golgher, Amaral e Neves (2015), investigaram também o desempenho dos alunos por meio do rendimento acadêmico semestral, separando os beneficiados pelo programa de assistência da época (denominado bônus sociorracial) e equiparando-os com os demais, que era equivalente. O resultado, novamente, foi sobre eficácia. 
- Velloso (2013), identificou uma diferença de desempenho de aproximadamente menos de um terço no conjunto das médias dos grupos cotistas dos de livre competição. Inclusive, houve situações nas quais os cotistas conseguiram até mesmo média superior. A diferença de desempenho, como visto, encaixa-se sobre eficácia.

- Bezerra e Gurgel (2012) apontaram na mesma direção, sugerindo que cotistas e não cotistas tinham desempenho similar. Ademais, encontraram que a evasão dos cotistas é menor do que os oriundos de ampla concorrência. A análise quantitativa, exemplifica a mesma coisa dos demais trabalhos: análise sobre a eficácia.

\section{Formulação de um Constructo para a Avaliação da Lei de Cotas}

Este trabalho tem como objetivo fornecer uma ferramenta para que gestores, legisladores e sociedade possam avaliar a Lei de Cotas baseada nos 3E's da administração pública, caros ao modelo gerencialista. Por meio da revisão de literatura, e como visto, os esforços até então feitos para interpretar essa lei não se basearam em uma perspectiva sobre a efetividade e eficiência da Lei, encontradas no bojo da administração pública gerencial. Quase a totalidade delas, se não a totalidade, confundem efetividade e eficiência com eficácia. Isso causa enorme estranheza, dado que já existem documentos e ferramentas publicitadas, que permitiriam melhor compreensão da lei. Assim, tudo o que foi encontrado até então, explicita a interpretação da aplicação da Lei per se, e não na sua compreensão holística sobre suas consequências. Os estudos, até então realizados, buscam identificar se os alunos cotistas atingem o desempenho próximo ao dos demais, se os percentis estão sendo cumpridos, se há evasão, se os egressos estão inseridos no mercado de trabalho sem comparar onde estariam sem a lei, etc.

Assim, para estabelecer uma ferramenta baseada nos 3E's, não se pode voltar inicialmente para análise do que a Lei propõe, mas sim seu objetivo, no qual ela é utensílio, e não fim. Firmando isso, fez-se o seguinte esboço da árvore de avaliação. Nela, vê-se os seguintes elementos:

- Na base, está a presunção adotada para a lei, e a primeira indagação;

- Baseado nas presunções, leva-se ao problema que busca ser selecionado;

- Como foi visto, a maior parte das leituras sobre a lei focam na eficácia, e não na efetividade, assim a analise busca contemplar os 3E's, melhores descritos na Tabela 1;

- Acima, os elementos centrais que devem ser tomados na avaliação: periodicidade contínua é fundamental em toda interpretação de qualquer política pública; a lei em si tem que ser estudada e esmiuçada para entender se ela faz sentido em si; a parte textual também carece de reflexão; uma série de indicadores plurais devem ser levantados; a lei tem que ser avaliada holisticamente; e a especificação dos agentes que a interpretariam;

Chegar-se-ia assim, no objetivo final, que responderia ao objetivo da árvore: saber se a lei de cotas é efetiva, eficaz e eficiente. 
Research, Society and Development, v. 10, n. 1, e51410112078, 2021

(CC BY 4.0) | ISSN 2525-3409 | DOI: http://dx.doi.org/10.33448/rsd-v10i1.12078

Figura 2.



Fonte: Autores (2021).

Como dito, para complementar essa ferramenta, foram elencadas diversas perguntas que sintetizam, exemplificam e direcionam características de cada um dos 3E's e como eles poderiam responder sobre o mérito da Lei. As perguntas foram selecionadas e transcritas na Tabela 1. 


\section{Tabela 1.}

\begin{tabular}{|c|c|c|}
\hline \multicolumn{3}{|l|}{ EFETIVIDADE } \\
\hline \multicolumn{3}{|c|}{ Perguntas que podem ser feitas dentro de cada campo } \\
\hline $\begin{array}{l}\text { Quantos cotistas estão } \\
\text { sendo inseridos no mercado de } \\
\text { trabalho na área que cursaram com } \\
\text { salários adequados? Que tipo de } \\
\text { acompanhamento e por que órgãos } \\
\text { governamentais? Como está sendo } \\
\text { o desempenho profissional deles? }\end{array}$ & $\begin{array}{l}\text { A Lei é a melhor forma } \\
\text { para diminuir a realidade entre os } \\
\text { grupos cotistas e os demais? Ela } \\
\text { pode ser considerada a melhor } \\
\text { forma até então? Há necessidade de } \\
\text { aperfeiçoamento? }\end{array}$ & $\begin{array}{l}\text { As cotas estão atingindo o } \\
\text { seu público correto? Os estudantes } \\
\text { que vem da escola pública } \\
\text { realmente tem educação inferior } \\
\text { aos da escola particular? Como } \\
\text { isso é provado? Existem algumas } \\
\text { escolas públicas aprovando mais } \\
\text { que outras? }\end{array}$ \\
\hline $\begin{array}{l}\text { As escolas particulares } \\
\text { estão sendo prejudicadas? Os } \\
\text { cursinhos propedêuticos têm } \\
\text { recebido alunos das escolas } \\
\text { públicas? Está ocorrendo migração } \\
\text { de alunos para o ensino público } \\
\text { para que eles possam se valer das } \\
\text { leis de cotas? }\end{array}$ & $\begin{array}{l}\text { Qual o custo da Lei de } \\
\text { Cotas para as Universidades e para } \\
\text { a sociedade? A sociedade como um } \\
\text { todo está arcando com isso ou } \\
\text { apenas grupos sociais restritos? }\end{array}$ & $\begin{array}{l}\text { Os cotistas estão ficando } \\
\text { na universidade? Estão evadindo? } \\
\text { Em que proporção? Se evadem, } \\
\text { qual o motivo? Como se dá o } \\
\text { controle? Seriam evasões } \\
\text { reversíveis ou irreversíveis? }\end{array}$ \\
\hline $\begin{array}{l}\text { O nível de educação no } \\
\text { Brasil como um todo tem crescido? } \\
\text { O Brasil tem se preparado através } \\
\text { de programas de educação para } \\
\text { melhorar os níveis da educação } \\
\text { básica? }\end{array}$ & $\begin{array}{l}\text { Como os mecanismos de avaliação } \\
\text { da Lei por membros distintos da } \\
\text { sociedade foram pensados e como } \\
\text { estão sendo implementados? } \\
\text { Pessoas contra a lei estão sendo } \\
\text { chamadas para o debate? } \\
\text { Como tem se encontrado na } \\
\text { sociedade os representantes de cada } \\
\text { grupo? }\end{array}$ & $\begin{array}{l}\text { Existe equidade na disputa entre } \\
\text { todos os cotistas dos mesmos } \\
\text { grupos? Os cotistas representam a } \\
\text { realidade das camadas mais } \\
\text { pobres, ou tem uma situação } \\
\text { privilegiada perante os demais? } \\
\text { Um indígena criado e } \\
\text { educado em uma comunidade } \\
\text { indígena (em língua tribal) } \\
\text { compete em pé de igualdade com } \\
\text { outra pessoa com traços indígenas } \\
\text { criada e educada em português? O } \\
\text { negro quilombola } \\
\text { concorrendo com outro negro } \\
\text { quilombola ou com um pardo de } \\
\text { pele clara criado em centros } \\
\text { urbanos e com acesso a diversas } \\
\text { formas de educação? } \\
\text { Os deficientes estão } \\
\text { competindo entre si de maneira } \\
\text { lógica e racional? As deficiências } \\
\text { estão sendo enquadradas em } \\
\text { deficiências menores concorrem } \\
\text { com graus mais elevados? }\end{array}$ \\
\hline
\end{tabular}




\begin{tabular}{|c|c|c|}
\hline $\begin{array}{l}\text { O que ocorre com os } \\
\text { prejudicados pela Lei? Eles têm } \\
\text { recursos para entrar em outras } \\
\text { Universidades? Estão estudando } \\
\text { normalmente? }\end{array}$ & $\begin{array}{l}\text { Quanto custa e qual o } \\
\text { tempo demandado para a contínua } \\
\text { análise da Lei? }\end{array}$ & $\begin{array}{l}\text { Os cotistas estão se } \\
\text { formando? Em quanto tempo? } \\
\text { Qual a comparação para os } \\
\text { demais? E historicamente? }\end{array}$ \\
\hline $\begin{array}{l}\text { Os candidatos aprovados e } \\
\text { formados estão devolvendo os } \\
\text { benefícios para os grupos sociais } \\
\text { que representam? }\end{array}$ & $\begin{array}{l}\text { O tempo para resultados está se } \\
\text { mostrando adequado? Haverá } \\
\text { necessidade de expansão? }\end{array}$ & $\begin{array}{l}\text { Os candidatos negros e } \\
\text { pardos são realmente vítimas de } \\
\text { preconceito racial para } \\
\text { ingressarem no mercado de } \\
\text { trabalho e dependiam das cotas } \\
\text { para romper essa barreira? }\end{array}$ \\
\hline $\begin{array}{l}\text { Que indicadores plurais } \\
\text { estão sendo trabalhados pelos } \\
\text { órgãos de controle? Estão sendo } \\
\text { satisfatórios? }\end{array}$ & $\begin{array}{l}\text { Os mecanismos anti-fraude } \\
\text { estão funcionando? Quais tem } \\
\text { funcionado? Há compartilhamento } \\
\text { de boas práticas entre as } \\
\text { universidades para evitar as } \\
\text { fraudes? }\end{array}$ & $\begin{array}{l}\text { Existem brechas legais que } \\
\text { podem facilitar pessoas que não } \\
\text { deveriam se beneficiar da lei, mas } \\
\text { mesmo assim se beneficiam? }\end{array}$ \\
\hline $\begin{array}{l}\text { As cotas têm diminuído os } \\
\text { preconceitos raciais no Brasil de } \\
\text { forma geral? E no mercado de } \\
\text { trabalho? }\end{array}$ & $\begin{array}{l}\text { Como as pesquisas para } \\
\text { avaliar a eficiência da lei estão } \\
\text { sendo feitas? Elas têm demonstrado } \\
\text { a eficiência da Lei? Quanto tem } \\
\text { custado essas pesquisas, onde e de } \\
\text { que forma estão sendo exibidas? }\end{array}$ & $\begin{array}{l}\text { Quando se detecta dados } \\
\text { interessantes, como o melhor } \\
\text { desempenho de cotistas em } \\
\text { determinada matéria, de que forma } \\
\text { isso é abordado? Como isso é } \\
\text { adotado? }\end{array}$ \\
\hline $\begin{array}{l}\text { As escolas públicas no } \\
\text { Brasil têm melhorado o seu ensino } \\
\text { em virtude da Lei? Como isso tem } \\
\text { sido avaliado? Existe diferença } \\
\text { entre as escolas públicas? Algumas } \\
\text { tem se saído melhor ou pior que } \\
\text { outras? }\end{array}$ & $\begin{array}{l}\text { As famílias que estão } \\
\text { ingressando seus filhos nas IES } \\
\text { públicas precisariam realmente } \\
\text { deste tipo de benefício? Qual a } \\
\text { realidade delas se comparado aos } \\
\text { demais? Qual a melhor forma de se } \\
\text { calcular essa estatística? Média? } \\
\text { Mediana? }\end{array}$ & \\
\hline $\begin{array}{l}\text { O tempo de estudo por } \\
\text { parte dos alunos tem aumentado } \\
\text { em virtude da Lei de Cotas? Existe } \\
\text { diferença dessa oscilação por } \\
\text { grupos raciais? Sociais? Que } \\
\text { outros dados podem ser vistos nas } \\
\text { escolas em virtude da LC? }\end{array}$ & $\begin{array}{l}\text { Quais os dados } \\
\text { demográficos que os cotistas têm } \\
\text { trazido a administração pública } \\
\text { para a criação de melhores políticas } \\
\text { públicas, de forma a não mais se } \\
\text { precisar das cotas? }\end{array}$ & \\
\hline $\begin{array}{l}\text { Existem medidas de } \\
\text { controle e apoio a entrada no } \\
\text { mercado de trabalho ou não é } \\
\text { necessário? }\end{array}$ & $\begin{array}{l}\text { Como estão sendo } \\
\text { trabalhadas políticas de apoio as } \\
\text { cotas? Quais são elas? }\end{array}$ & \\
\hline
\end{tabular}

Fonte: Autores (2021). 


\section{Considerações Finais}

Como visto, a Lei de Cotas 12.711/12 foi uma das grandes iniciativas adotadas no Brasil para facilitar o acesso as IES públicas. Todavia, a lei que tem durabilidade inicial de dez anos, ainda carece vigorosamente de análise, faltando pouco menos de dois anos para que a mesma seja revista. Assim, este trabalho buscou levantar como essa lei tem sido discutida pela perspectiva da administração pública gerencial, tomando como base os 3E's. Viu-se, claramente, que existe uma enorme confusão por parte dos autores, inclusive agentes públicos e comitês formados, para dissociar a ideia de efetividade e eficiência de eficácia. Ser eficaz não quer dizer de maneira nenhuma ser eficiente nem tampouco efetivo. Aliás, como pontua Reis (2014), deve-se sempre buscar as melhores decisões, a fim de que essas possam atender o interesse nacional de maneira eficaz e eficiente. Logo, efetividade é mais importante que essas duas. A historicidade da administração pública gerencial demonstrou claramente a importância da interação entre as três, principalmente em um cenário democrático, reforçando o momento histórico e o seu contexto atual, validando que para se mensurar uma lei interpretações diversas têm características dentro da ciência administrativa, refletidas no modelo 3E's: a Burocracia = eficiência, Gerencial = eficácia, pós-gerencial = efetividade.

Nota-se que a Lei carece de infinitos indicadores, e que os pouco que existem, são absolutamente fracos, o que foi demonstrado claramente na análise do relatório sobre a "efetividade" da Lei de Cotas carioca, onde o Comitê utilizou entrevistas da Revista Veja. Outrossim, sabe-se que muitas das perguntas levantadas na Tabela 1 não conseguem ser respondidas através de nenhum dado existente por ora. A inexistência de um comitê avaliativo, distribuído pelo país, e em operação desde 2012, não é compatível com o modelo gerencialista em voga desde a década de 1980 no mundo. Isso pode sugerir que Leis populistas com apelo social, ainda podem trazer aceitação, mas uma análise crítica das mesmas, pode (como foi o caso) explicitar a debilidade das mesmas, resultando em consequências graves, como a não satisfação das necessidades dos reais interessados e da sociedade no geral.

Desta forma, o trabalho atendeu os seus dois objetivos principais, que eram analisar e interpretar como a Lei de Cotas vem sendo mensurada, e na sequência, propor um modelo mais robusto para avaliar essa política a luz da administração pública gerencial. Como principal limitação, destaca-se o caráter exploratório do trabalho, bem como sua proposição e espaço reduzido para se refletir sobre tudo que ele proporia. Segue-se, assim, como proposta de estudos futuros, que esse modelo seja aplicado na íntegra, buscando responde-lo de ponta a ponta. Outro trabalho interessante, seria apresentar o modelo elaborado a pesquisadores de efetividade, eficácia e eficiência na administração pública, e investigar se ele estaria adequado ou quais pontos estão insuficientes.

\section{Referências}

Almeida, F. M. S., \& Rodrigues, C. T. (2020). Avaliação da política de cotas na Universidade Federal de Viçosa. Planejamento e Políticas Públicas, n. 53.

Araújo, L. M., \& Rodrigues, M. I. A. (2012). A relação entre os princípios da eficiência e da economicidade nos contratos administrativos. Revista do Serviço Público, 63(1), 43-62.

Basso-poletto, D., Efrom, C., \& Beatriz-rodrigues, M. (2020). Ações Afirmativas no Ensino Superior: revisão quantitativa e qualitativa de literatura. Educare, Heredia, 24(1), 292-325.

Bezerra, T. O. C., \& Gurgel, C. R. M. (2012). A política pública de cotas em universidades, enquanto instrumento de inclusão social. Pensamento \& Realidade, 27(2), 95-117.

Botelho, L., Cunha, C., \& Macedo, M. (2011). O método da revisão integrativa nos estudos organizacionais. Gestão e Sociedade, 5(11), 121-136.

Brasil, F. G., Cepêda, V. A., \& Medeiros, T. B. (2014). O DASP e a formação de um pensamento político-administrativo na década de 1930 no Brasil. Temas de Administração Pública, 9(1).

Brasil. (1998). Emenda Constitucional no 19, de 4 de junho de 1998: Modifica o regime e dispõe sobre princípios e normas da Administração Pública, servidores e agentes políticos, controle de despesas e finanças públicas e custeio de atividades a cargo do Distrito Federal, e dá outras providências. Diário Oficial da República Federativa do Brasil.

Bresser-pereira, L. C. (1996). Da administração pública burocrática à gerencial. Revista do Serviço Público, 120(1), 07-40. 
Bresser-pereira, L. C. (2005). Réplica: comparação impossível. Revista de Administração de Empresas, 45(1), 50-52.

Cardoso, T. G. (2016). Lei de cotas e a escolha de escola no ensino básico. Tese de Doutorado. Universidade de São Paulo.

Casa Civil. (2018). Avaliação de políticas públicas: guia prático de análise ex post. Brasília: Casa Civil da Presidência da República.

Catani, A., Hey, A. P., \& Gilioli, R. (2006). PROUNI: democratização do acesso às Instituições de Ensino Superior?. Revista Educação, 1(28).

Cordeiro, A. M. et al. (2007). Revisão sistemática: uma revisão narrativa. Rev. Col. Bras. Cir, 34(6), 428-431.

Costa, F. L., \& Castanhar, J. C. (2003). Avaliação de programas públicos: desafios conceituais e metodológicos. Revista de Administração Pública, 37(50), 969-992.

Cunha, C. G. S. da. (2018). Avaliação de Políticas Públicas e Programas Governamentais: tendências recentes e experiências no Brasil. Revista Estudos de Planejamento, 12.

Da Costa Garcia, F., \& de Jesus, A. G. R. (2015). Uma avaliação do sistema de cotas raciais da Universidade de Brasília. Fundação Carlos Chagas, 26(21).

Golgher, A., Amaral, E. F. L., \& Neves, A. V. C. (2015). Desempenho acadêmico dos estudantes da UFMG: Uma análise da política de bônus sociorracial. Ciências Sociais em Perspectiva, 14(26), 120-145.

Guimarães, A. S. A., \& ios, F. M. (2014). Cotas nas universidades públicas. Afro-Ásia, 50(1), 251-256.

Marchesan, F, \& Oliveira, O. S. (2019). Avaliação da efetividade de uma política pública: ação afirmativa para a agricultura familiar no Campus Concórdia. Jornal de Políticas Educacionais, 13(36).

MEC. (2020). Ensino Superior: entenda as cotas para quem estudou todo o ensino médio em escolas públicas. Legislação. http://portal.mec.gov.br/cotas/legislacao.html

Menezes, J. B. (2005). O princípio da eficiência na administração pública brasileira: instrumentalização, destinação e controle. Pensar-Revista de Ciências Jurídicas, 10(1), 57-66.

Moreira, W. (2004). Revisão de literatura e desenvolvimento científico. Janus, 1(1).

Osborne, D., \& Gaebler, T. (1994). Reinventando o Governo: como o espírito empreendedor está transformando o setor público. Brasília: MH Comunicação.

Palma, V. C. L. C. F. et al. (2019). Educação, democracia e inclusão racial: análise da efetividade da lei de cotas para negros em concursos docentes de universidades federais. Escola de Administração da Universidade Federal da Bahia, 11(20).

Paula, A. P. P. (2005). Administração pública brasileira entre o gerencialismo e a gestão social. Revista de administração de empresas, 45(1), 36-49.

Pereira A. S. et al. (2018). Metodologia da pesquisa científica. Ed. UAB/NTE/UFSM. https://repositorio.ufsm.br/bitstream/handle/1/15824/Lic_Compu tacao_Metodologia-Pesquisa-Cientifica.pdf?sequence=1.

PGE-RJ. (2017). Procuradoria Geral do Estado do Rio de Janeiro. Relatório Final sobre a Efetividade da Lei de Cotas nas Universidades Estaduais. Recuperado de: https://pge.rj.gov.br/entendimentos/relatorios.

Ramos, M. P., \& Schabbach, L. M. (2012). O estado da arte da avaliação de políticas públicas: conceituação e exemplos de avaliação no Brasil. Revista de administração pública, 46(5), 1271-1294.

Reis, M. L. (2014). Reforma do Estado: da Administração Burocrática à Administração Pública Gerencial: o caso brasileiro. Revista Foco, 7(1), 104-137.

Ribeiro, F. M., \& Guzzo, R. S. L. (2017). Consciência de Estudantes Prounistas sobre sua Inserção no Ensino Superior. Psicol. cienc. prof., 37(2), $418-431$.

Rio de Janeiro (2008). Lei Estadual n ${ }^{\circ} 5346$, de 11 de dezembro de 2008. Poder Executivo, Rio de Janeiro.

Sano, H., \& Montenegro Filho, M. J. F. (2013). As técnicas de avaliação da eficiência, eficácia e efetividade na gestão pública e sua relevância para o desenvolvimento social e das ações públicas. Desenvolvimento em questão, 11(22), 35-61.

Secch, L. (2009). Modelos organizacionais e reformas da administração pública. Revista de Administração Pública, 43(2), 347-369.

Souza, C. (2007). Estado da arte da pesquisa em políticas públicas. Políticas públicas no Brasil. Rio de Janeiro: Fiocruz, 65-86.

Vergara, S. C. (2009). Projetos e Relatórios de Pesquisa em Administração (11a ed.). Atlas. 